\title{
Awakening Interest in the Natural Sciences - BASF's Kids' Labs
}

\author{
Cinthia Lang*
}

\begin{abstract}
At BASF's Ludwigshafen headquarters, kids and young adults in grades 1-13 can learn about chemistry in the Kids' Labs. Different programs exist for different levels of knowledge. In the two 'Hands-on Lab $\mathrm{H}_{2} \mathrm{O}$ \& Co.' Kids' Labs, students from grades 1-6 explore the secrets of chemistry. BASF Kids' Labs have now been set up in over 30 countries. In Switzerland alone, almost 2,000 students have taken part in the 'Water Loves Chemistry' Kids' Lab since it was started in 2011. In Alsace, 600 students have participated to date. In the Teens' Lab 'Xplore Middle School', middle school students explore five different programs with the themes 'substance labyrinth', 'nutrition', 'coffee, caffeine \& co.', 'cosmetics' and 'energy'. Biotechnological methods are the focus of the Teens' Lab 'Xplore Biotech' for students taking basic and advanced biology courses. In the 'Xplore High School' Teens' Lab, chemistry teachers present their own experimental lab instruction for students in basic and advanced chemistry courses. The Virtual Lab has been expanding the offerings of the BASF Kids' Labs since 2011. The online lab was developed by the company for the International Year Of Chemistry and gives kids and young adults the opportunity to do interactive experiments outside of the lab.
\end{abstract}

Keywords: Experiments · Hands-on labs $\cdot$ Kids and chemistry

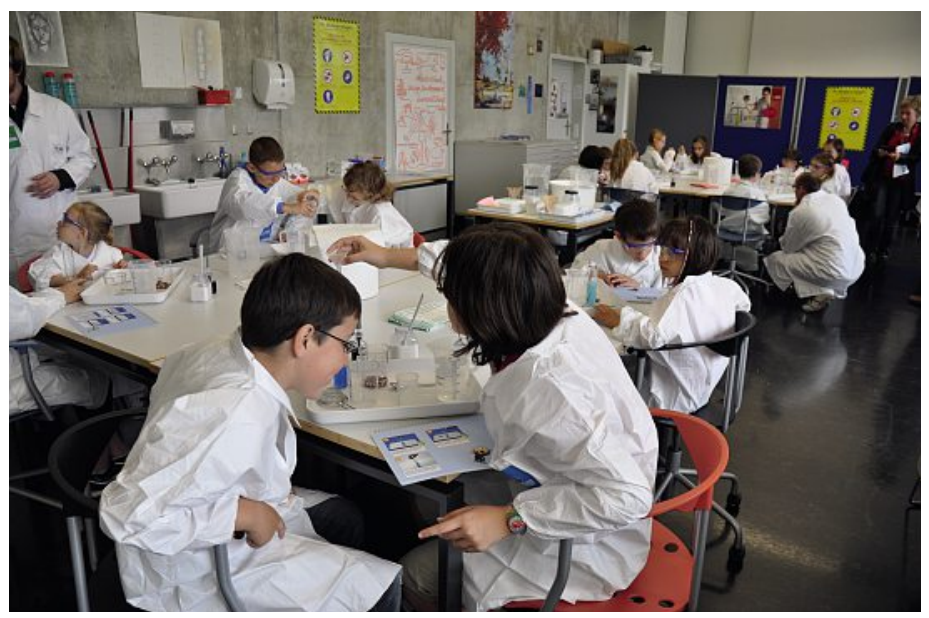

Kids' Lab: The event begins.

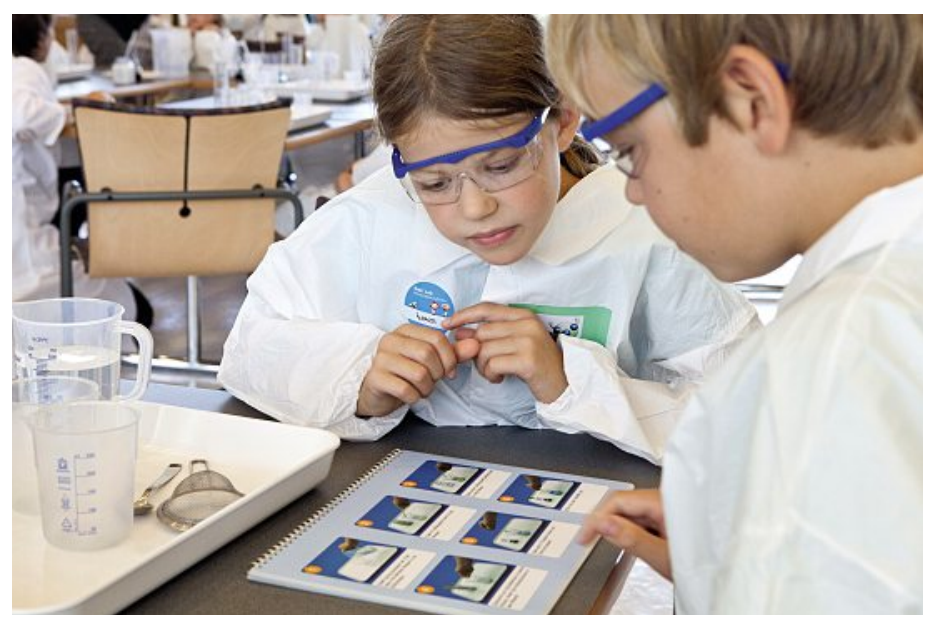

Students read instructions before the next step.
Through targeted sponsoring of humanitarian, social and cultural matters, BASF SE contributes to the positive development of society. The company is involved in the communities in which its activities are located. Education and science is one of the main focuses of such sponsoring. At the Ludwigshafen location, students from the Rhein-Neckar Metropolitan Region can experience it for themselves and become
${ }^{*}$ Correspondence: C. Lang

BASF Schweiz AG

Klybeckstrasse 141

$\mathrm{CH}-4057$ Basel

Tel.: +41616361228

E-mail: cinthia.lang@basf.com researchers at the five BASF Kids' Labs. Different programs exist for different levels of knowledge. From 7th grade onwards, instruction programmes are based on the curricula of the respective grades. Every year over 18,000 students experiment both independently and with the assistance of expert instructors in the labs. By providing this opportunity, BASF aims to promote interest in the natural sciences among kids and young adults.

\section{Kids' Lab: Unlocking the Mysteries of Everyday Life}

In the two Kids' Labs - 'Hands-on Lab $\mathrm{H}_{2} \mathrm{O}$ \& Co.' - students from grades 1-6 get their first chance to give chemistry a try. Through independent experimentation, they examine natural phenomena from their everyday lives in an entertaining manner and learn that chemical inventions are not only exciting, but also useful. The Kids' Lab draws on years of experience. Started in June 1997, the hands-on lab ' $\mathrm{H}_{2} \mathrm{O}$ \& Co.' was redesigned and in January 2007 its capacity was doubled with its move to the visitor center. Since June 2007, two school classes have been able to visit the labs each day. In the lab for grades 1-4, Dr. Blubber, Nelly Natron, Paul Polymer and Fabs take kids on a fascinating journey through the history of chemistry. In the 'alchemist's cellar', the kids learn how to work with various tools of chemistry. In order to help Dr. Blubber solve his alchemist's riddle, they have to weigh, mix or separate substances. In the 'chemix kitchen', kids learn 
that chemistry is all around us, including in the household. Why is hibiscus tea blue one time and pink another? To answer the question, the kids have to think up simple experiments themselves. Clever ideas and trial and error lead them to the answer. Paul Polymer assists the kids as they examine modern chemical compounds like superabsorbent polymers in the 'inventor's lab'. They learn how to formulate research questions and answer them using simple experiments. This promotes observation skills and analytical thinking.

The interactive hands-on exhibit 'All chemistry?!' adds an extra dimension beyond the experimentation stations. Touching is encouraged: Specially developed for kids, the different components of the exhibit invite kids to discover, touch and try new things. A new addition to the exhibit is a piece dealing with energy: Kids can light up a light-bulb lamp or a LED, or power a radio with muscle-power. Kids learn about how much energy is in different foods when they open the exhibit's refrigerator. In the 'wardrobe' section, kids find out what materials their clothes are made of and how differently natural and artificial materials feel to the touch. In the 'bathroom', students identify different fragrances and learn what toothpaste, lotions and shower gel are made of.

Since 2008, fifth and sixth graders have had their own program. Three research stations give kids the chance to experiment creatively. In 'Paul's Poly-Lab', for example, students examine the question of how plastics can be re-used or made from renewable raw materials. In 'Nelly's Color Lab', kids create a paint out of water-insoluble food coloring. Precise observation and clever combination of the source materials are the keys to success here. At the third station, the hands-on lab 'All chemistry?!', students research natural science topics in teams and present their results to the research council. Creativity is key here.

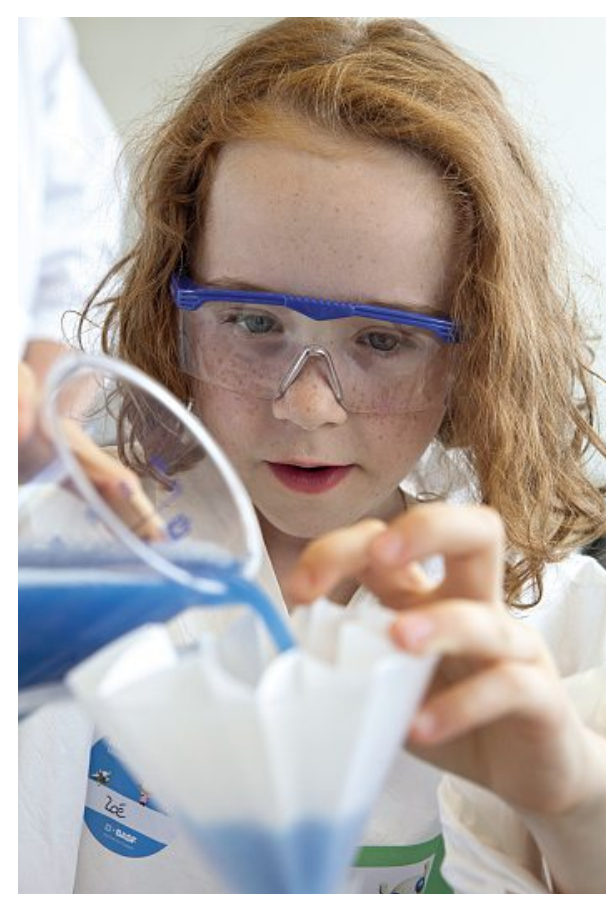

The coloring agent is poured with care.

\section{Teens' Lab: Experiencing Chemistry and Biotechnology}

The three teens' labs - Xplore Middle School, Xplore Biotech and Explore High School - for students in grades 7-13 also emphasize hands-on experience. The middle school and high school students are led by scientists and student teachers in chemistry or biology. BASF has offered the Teens' Labs and the biotechnology labs for middle school students since October 2001, and the Teens' Lab for high school students since November 2005. BASF also uses the labs for teacher training courses. Students in grades 7-10 work on different topics depending on their grade in the Teens' Lab - Xplore Middle School. In the 'substance labyrinth', younger students have their first contact with experimental chemistry. The students identify unknown substances by means of various experiments. In the 'coffee' project for more advanced students, various material separation operations are the focus. Distillation, extraction, chromatography: Using these methods, the students follow the processing process from the green coffee bean to the instant coffee it becomes. In the 'nutrition' project, students in grades 7-9 assume the role of a food chemist and examine various food and beverage samples. In the project for ninth and tenth graders, students delve into the world of cosmetics and fragrances. Just for girls? Not a chance. Many boys of this age won't leave the house without hair gel. The experiment series for tenth graders goes under the heading 'Energy'. The energy sources hydrogen and biodiesel as well as various ways of saving energy are the focus of this unit. The Teens' Lab Xplore Biotech is directed at high school students in basic or advanced biology. In advanced experiments, they learn to use the methods of genetic engineering and apply their knowledge in practice. For example, they transfer genetic material to a receiver medium or characterize DNA fragments. Following the experimental unit, they discuss the opportunities and risks presented by biotechnology and genetic engineering.

The Teens' Lab - Xplore High School, by contrast, follows a completely different approach. In a well-equipped, large lab, chemistry teachers can conduct their own experimental class instruction. From a range of different experiments, they choose the ones that most suit their instruction topics. We also welcome teachers' own subjects and experiments. They are advised and assisted by a qualified team of BASF employees. In the Teens' Lab for Advanced Students, teachers and students can conduct more advanced experiments for which schools lack the equipment, space or safety equipment. Another benefit: Twelve fully equipped lab stations including flues are available for up to 24 students, who can

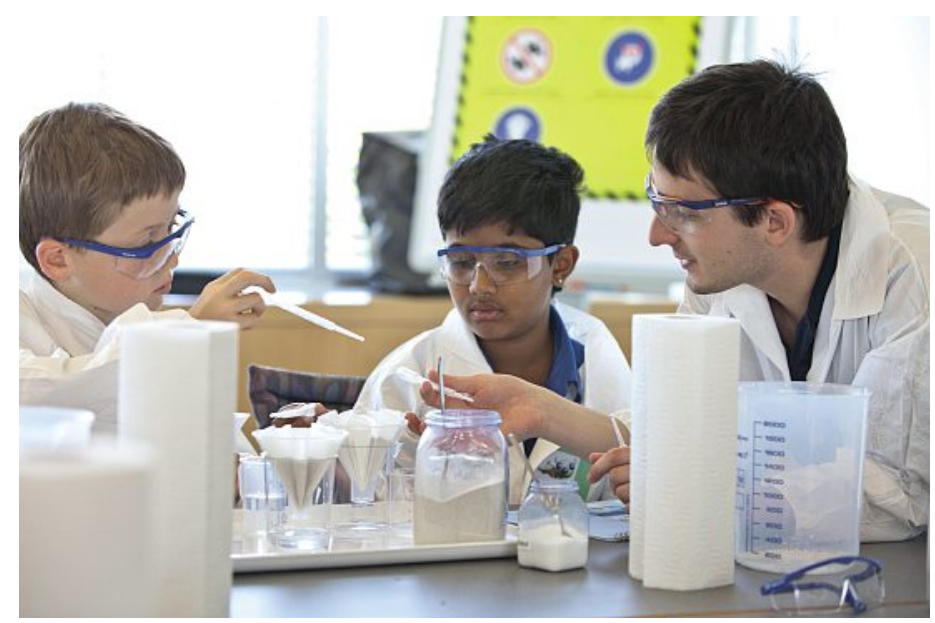

A BASF employee accompanies the kids throughout the experiment and answers their questions.

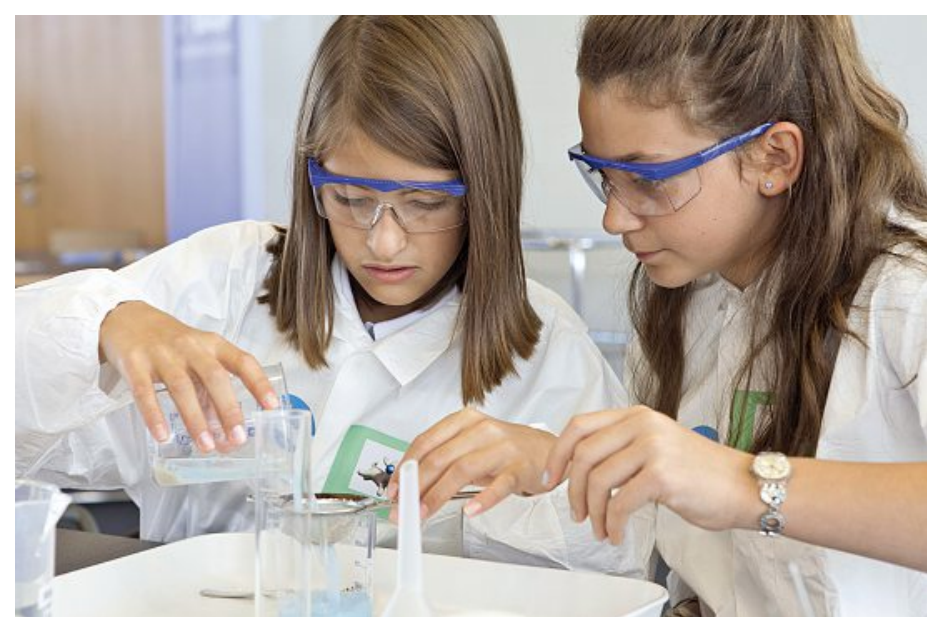

Two girls attempt the 'clean water' experiment. 


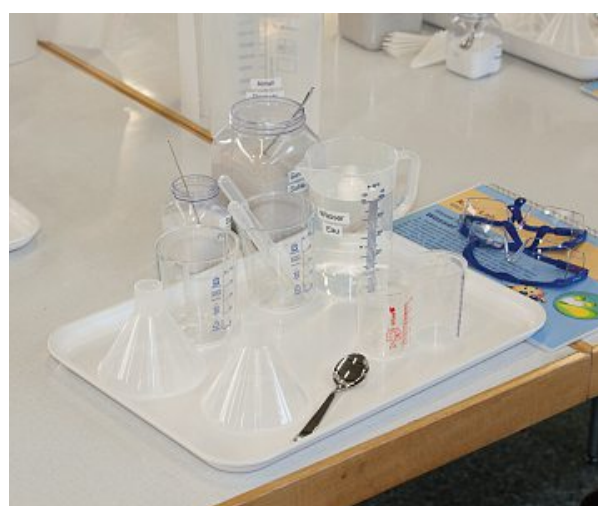

Overview of materials used.

experiment independently using prepared instructions. BASF currently offers experiments from the fields of nanotechnology, energy, acid-base titrations, redox titrations, electrochemistry, organic synthesis, extractions, plastics, coloring agents, analytics and catalysis.

\section{The Kids' Lab Goes on the Road}

BASF has also exported the idea of Kids' Labs to other countries. Since 2002 BASF has held highly successful one-day events in countries such as China, India and Thailand, in which 6-12 year-olds are given the chance to carry out experiments and discover their passion for the natural sciences. While the labs in Ludwigshafen are stationary, BASF's worldwide Kids' Labs have an event-like feel or are run in cooperation with science centers. During the International Year of Chemistry in 2011, the experimentation program 'Water Loves Chemistry' has traveled the world, bringing BASF Kids' Labs to 33 countries to date. In Switzerland, almost 2,000 kids have taken part in Kids' Labs since 2011. In Alsace, 600 students have participated.

\section{Instructional Materials and More via Internet}

The portal for our BASF Ludwigshafen branch not only features information for kids and young adults but also a range of offerings for teachers and chemistry buffs on its 'BASF \& Schools' page (http:// www.basf.com/group/corporate/site-ludwigshafen/en/about-basf/worldwide/europe/Ludwigshafen/Education/index). In addition to event tips, current information and various types of instructional materials, you can also find a range of chemistryrelated interactive features. From online chemistry sudoku to a challenging element quiz to interesting podcasts, the site has something for people of all ages. You can also view visual representations of topics from the worlds of biotechnology and genetic engineering. Scientifically based yet play-based and entertaining, BASF's online biotech lab aims to provide a forum for engaging with the hot topic of biotechnology. It is open to anyone who is interested in biotechnology and genetic engineering. The virtual lab is found at www.xplore-biotech.de.

Received: September 25, 2012 